\title{
NOVEL APPROACH FOR ESTIMATING NITROGEN CONTENT IN PADDY FIELDS USING LOW ALTITUDE REMOTE SENSING SYSTEM
}

\author{
M. M. Saberioon ${ }^{\text {a }}$, A. Gholizadeh ${ }^{\text {b }}$ \\ ${ }^{a}$ Laboratory of Signal and Image Processing, Institute of Complex Systems, Faculty of Fisheries and Protection of Waters, South \\ Bohemian Research Center of Aquaculture and Biodiversity of Hydrocenoses, University of South Bohemia in Ceske Budejovice, \\ Zámek 136, Nové Hrady 373 33, Czech Republic - msaberioon@frov.jcu.cz \\ ${ }^{\mathrm{b}}$ Department of Soil Science and Soil Protection, Czech University of Life Sciences Prague, 16521 Prague, Czech Republic - \\ gholizadeh@af.czu.cz
}

Commission I, ICWG I/Vb

KEY WORDS: Low altitude remote sensing, Unmanned aerial vehicle, Rice, Vegetation index, Nitrogen

\begin{abstract}
:
Concerns over the use of nitrogen have been increasing due to the high cost of fertilizers and environmental pollutions caused by excess nitrogen application in agricultural fields. Several methods are available to assess the amount of nitrogen in crops, however, they are expensive, time-consuming, inaccurate, and/or require specialists to operate the tools. Researcher recently suggested remote sensing and specifically Low Altitude Remote Sensing (LARS) system of chlorophyll content in crop canopies as a low-cost alternative to estimate plant nitrogen status. The main objective of this study was to develop and test a new Vegetation Index (VI) to determine the status of nitrogen and chlorophyll content in rice leaf by analysing and considering all Visible (Vis) bands. Besides, capability of introduced VI has compared with all known VIs in both Vis and Near Infrared (NIR) bands in canopy scale. To develop the VI, images from 6-pannel leaf colour chart were acquired using Basler Scout scA640-70fc under light-emitting diode lighting, in which principal component analysis was used to retain the lower order principal component to develop a new index called $I_{P C A}$. A conventional digital camera mounted to an Unmanned Aerial Vehicle (UAV) was also used to acquire images over the rice canopy in Vis bands. Simultaneously, Tetracam agriculture digital camera was employed to acquire rice canopy image in Vis-NIR bands. The results indicated that the proposed index at canopy $(\mathrm{r}=0.78)$ scale could be used as a sensor to determine the status of chlorophyll content consequently for monitoring nitrogen in rice plant through different growth stages. Moreover, results confirmed that a lowcost LARS system would be suited for high spatial and temporal resolution images and data analysis for proper assessment of key nutrients in crop farming in a fast, inexpensive and non-destructive way.
\end{abstract}

\section{INTRODUCTION}

Nitrogen $(\mathrm{N})$ is the most widely used fertilizer nutrient in rice cultivation and its consumption has increased in recent decades. Plant growth and crop production require plentiful $\mathrm{N}$ and $\mathrm{N}$ deficiency causes a reduction in Leaf Area Index (LAI), radiation use efficiency and photosynthesis activity in plant (Fageria and Baligar, 2005). Therefore, knowledge of $\mathrm{N}$ status of crop is essential for sustainable management of $\mathrm{N}$ fertilizer (Huber and Thompson, 2007). There are several reason mentioned in literature for low $\mathrm{N}$ use efficiency, however, the most important reason is an inefficient splitting of $\mathrm{N}$ doses coupled with $\mathrm{N}$ applications in excess of crop requirements (Varinderpal-Singh et al.,2010).

Management of $\mathrm{N}$ is an important aspect of improving crop productivity. An accurate prediction of $\mathrm{N}$ requirements during the cultivation period is also necessary for efficient fertilizer use. In other words, fertilizer application rates should be determined based on the crop requirement and its optimum nutrient levels at various parts of a paddy field to achieve economical, environmentally friendly and high-yield production.

Since mid-1980's research was oriented more toward matching crop $\mathrm{N}$ demand with fertilizer $\mathrm{N}$ supply for achieving high Nitrogen use efficiency (NUE) (Buresh, 2007) and finding means and ways to apply fertilizer $\mathrm{N}$ in real time using crop and field specific needs. This need has been more pronounced when the blanket recommendation consisting of three of four split applications of pre-set rates of total $\mathrm{N}$ fertilizer during the growing season of rice are commonly practiced by farmers for managing $\mathrm{N}$ fertilizer, because the rate of $\mathrm{N}$ uptake by rice changes during growth and development. Thus, sound $\mathrm{N}$ management practices need to be established in order to improve $\mathrm{N}$ uptake and usage efficiency, which leads to high grain yield, minimal $\mathrm{N}$ fertilizer losses, and reduce cost of rice production. To achieve these goals, the monitoring of crop $\mathrm{N}$ status is important for improving the balance between crop $\mathrm{N}$ demand and $\mathrm{N}$ supply from soil and fertilizer. By selecting a suitable method to evaluate the plant's nutrient status. It is possible to attain efficient $\mathrm{N}$ management in crops and particularly in rice plant. The ability to quickly and easily monitor a crop's $\mathrm{M}$ status as well as using the obtained information to optimize $\mathrm{N}$ fertilizer input would increase NUE. Currently several different, direct and indirect methods and instruments are available for assessing $\mathrm{N}$ status in crops and manage the amount of $\mathrm{N}$ fertilizer applied to crop based on sitespecific requirements such as tissue and chemical analysis, leaf colour chart (LCC), chlorophyll meter (Gholizadeh et al., 2011), Dualex (Cartelat et al., 2005), Greenseeker (Johanson et al., 2002), crop circle ACD-210 and crop circle ACD-470(Cao et al., 2013) and Yara passive N sensor. However, all of the above mentioned methods have been proven to be costly, time consuming and in some cases destructive and labor-intensive. Recently, remote sensing (RS) has become an attractive technique for crop nutrient determination (Link and Reusch, 2006). Among the different RS platforms, the low altitude remote sensing (LARS) system is currently attractive to researchers and agriculturists, which includes precision farming as one of the promising platforms for monitoring crops. Various LARS platforms are now available, such as tractor driven crane mounted system (Samseemoung et al., 2012), kites (Aber et al., 2002), blimps (Vericat et al., 2008), balloons (Jensen et al., 
2007) unmanned helicopters (Swain et al., 2010), unmanned aerial planes (Hunt et al., 2005), power gliders (Lelong et al., 2008) and quadcopter (Primicerio et al., 2012) to capture images for agriculture applications. Among the different LARS platforms, imagery using digital cameras attached to unmanned aerial vehicles (UAV) has attracted researchers the more because of their possibility to provide high spatial and temporal resolution images over the agriculture fields with low cost in compare to airborne and satellite platforms( Hunt et al., 2005).

All of these platforms which mentioned above are equipped with a variety pf types of remotely sensed sensors such as film cameras or commercial digital cameras (Teoh et al., 2012) and global navigation satellite systems which can acquire images with high resolution over the farms. Digital images record information as the amount of Red, Green and Blue (RGB) and have been used to measure crop N status with some success. For example, Mercado-Luna et al. (2010) used RGB colour space to determine N deficiency in tomato seedling. Pagola et al. (2009) used RGB colour space to estimate the status of $\mathrm{N}$ in barley. Lee and Lee (2013) used visible colour bands and Stepwise Multiple linear regression to develop a model for diagnosis of growth and $\mathrm{N}$ status in rice. Along with visible bands, reflectance in the Vis and NIR region have also been studied and proved to be a good indicator of nutrient status in many crops (Bajwa and Mozaffari, 2007; Lee et al., 2008) For instance, Xue et al. (2004) found that the ratio of reflectance at 819 and $560 \mathrm{~nm}$ has a robust relationship with leaf $\mathrm{N}$ concentration $\left(R^{2}=0.96\right)$ and chlorophyll meter $\left(R^{2}=0.90\right)$ in rice.

Studies on RS applications in agriculture have used vegetation indices (VIs) to evaluate the crop condition. VIs which are the combination of more than one band, are easy to use and would be an accurate and simple method in digital image analysis for evaluating and monitoring crop nutrients and biophysical paramreters (Hansen and Schjoerring, 2003). Moreover, VIs reduce large data volumes from RS to keep only useful information for management. VIs which are calculated form combination of red, green and blue bands have been studied and showed good performance for determining the status of plant nutrient. For example, Normalized Green Red difference index (NGRDI) shows sensitivity to different chlorophyll concentration in leaves (Hunt et al., 2005). Rorie et al., (2011a; 2011b) found that Dark Green Colour index (DGCI) have a close association with leaf N in corn. Furthermore, Hunt (2013) developed the Triangular Greenness Index (TGI) based on Vis bands for determining status of chlorophyll content in crops $\left(\mathrm{R}^{2}\right.$ $=0.85$ ).

Most indices are calculated using the ratio or normalized difference of two bands, which may not consider all three bands in the visible wavelengths. The main objective of this study was to develop and test a new index to determine the status of $\mathrm{N}$ and chlorophyll content in rice leaf by analysing and considering all visible bands derived from images captured using conventional digital camera and principal component analysis. Moreover, images from UAV were used to examine and capability of new developed index at the canopy scale. Simultaneously, Tetracam agriculture cameras was employed to acquire rice canopy image in Vis-NIR bands. Another objective of this experiment was to compare capability of new developed VI with Vis-NIR bands.

\section{MATERIALS AND METHODS}

\subsection{Field Preparation for Leaf Data}

Four different levels of $\mathrm{N}$ fertilization were applied to the pots, namely, a control with no added fertilizer (N0) and three other levels [N1 85 $\mathrm{kg} \mathrm{ha}^{-1}$ (acute shortage); N2 $170 \mathrm{~kg} \mathrm{ha}^{-1}$ (Normal practice). The pots were arranged in a randomized complete block design with four replicates and grown under flooded condition with spacing of $3 \mathrm{~m} \times 3 \mathrm{~m}$.P and $\mathrm{K}$ fertilizer rates were applied equally for all the treatments $\left(\mathrm{P}: 80 \mathrm{~kg} \mathrm{ha}^{-1}, \mathrm{~K}: 150 \mathrm{~kg}\right.$ $\mathrm{ha}^{-1}$ ).

\subsection{Leaf Data Acquisition}

The youngest fully expanded leaf was removed and transferred to laboratory immediately. Leaf were photographed using Basler scout camera with 2 mega pixel resolution under lightemitting diode (LED) light. Images saved as TIFF files. Parallel to photography, the same leaves chlorophyll were measured using SPAD -503.

\subsection{Development of Principal Component Analysis Index}

In order to calculate the Principal component analysis (PCA), firstly, each panel of a leaf colour chart (LCC) with scale of six green colour shades under LED light photographed, next the average values of difference between $R, G$ and $B$ calculated The values of $R-B$ and $G-B$ are the corrected values of $R$ and $G$ using $\mathrm{B}$ as a base. As this operation reduces the bias noise in $\mathrm{R}$, $\mathrm{G}$ and $\mathrm{B}$, the correlation of $\mathrm{R}-\mathrm{B}$ and $\mathrm{G}-\mathrm{B}$ with chlorophyll is higher than those of $\mathrm{R}$ and $\mathrm{G}$. Correlation matrix was then calculated using PCA to obtain the eigenvalues and eigenvectors as weights for each principal component. Finally the new index that is the value of eigenvector associated with the highest eigenvalue is as follows:

$$
\mathrm{IPCA}=0.994|\mathrm{R}-\mathrm{B}|+0.961|\mathrm{G}-\mathrm{B}|+0.914|\mathrm{G}-\mathrm{R}|
$$

Where $\mathrm{R}$ is red, $\mathrm{B}$ is blue and $\mathrm{G}$ is green.

\subsection{Imagery using Unmanned Aerial Vehicle}

Canopy data were captured during rice growing season in March 2013 at the Tanjung Karang Rice Irrigation Scheme located on a flat coastal plain in the integrated agriculture development area on latitude $335^{\prime} \mathrm{N}$ and longitude $10105^{\prime} \mathrm{E}$. Image were obtained using a Swinglet CAM on 25 March 2013 (71 Days After Plantation(DAP)) at 9:30 am. Swinglet CAM is a radio controlled model glider plane which is controlled by an autopilot computer program to take photograph at user-selected waypoint to ensure complete coverage of the field. Two different cameras attached to UAV for providing images. First group of images was provided by a compact digital camera with 16 megapixel resolution in JPEG format. Second group of images were provided using Tetracam agriculture digital camera as stored as Raw-8bit image. Tetracam agriculture digital camera had been calibrated by capturing the images from the Teflon calibration tag under the same lighting conditions as the images under study.

\subsection{Calculation of Indices}

In the study of leaf data, 288 images were analyzed based on 12 colour indices in visible bands and 3 indices in visible-NIR bands. The colour indices were obtained from the average colours of the whole image. The indices used for evaluation are listed and defined in Table 1.

\begin{tabular}{|l|c|c|}
\hline Name & Abbrev & Definition \\
\hline Normalized green red difference index & NGRDI & $(\mathrm{g}-\mathrm{r}) /(\mathrm{g}+\mathrm{r})$ \\
Kawashima index & $\mathrm{I}_{\mathrm{KAw}}$ & $(\mathrm{R}-\mathrm{B}) /(\mathrm{R}+\mathrm{B})$ \\
Excess red vegetation index & ExR & $1.4 \mathrm{r}-\mathrm{g}$ \\
Excess blue vegetation index & ExB & $1.4 \mathrm{~b}-\mathrm{g}$ \\
\cline { 2 - 3 } & &
\end{tabular}




\begin{tabular}{|c|c|c|}
\hline Excess green vegetation index & ExG & $2 g-r-b$ \\
\hline Excess green minus Excess red & ExGR & $\mathrm{ExG}-\mathrm{ExR}$ \\
\hline Green-red vegetation index & GRVI & $(G-R) /(G+R)$ \\
\hline Dark green colour index & DGCI & $\begin{array}{c}\{(\mathrm{H}-60) / 60+(1-\mathrm{S}) \\
+(1-\mathrm{Br}) / 3\}\end{array}$ \\
\hline Red green ratio index & RGRI & $\mathrm{R} / \mathrm{G}$ \\
\hline Green leaf index & GLI & $\begin{array}{c}(2 \mathrm{G}-\mathrm{R}-\mathrm{B}) /(2 \mathrm{G}+\mathrm{R} \\
+\mathrm{B})\end{array}$ \\
\hline $\begin{array}{l}\text { Visible atmospherically resistance } \\
\text { index }\end{array}$ & VARI & $(G-R) /(G+R-B)$ \\
\hline Principal component analysis index & $\mathrm{I}_{\mathrm{PCA}}$ & $\begin{array}{l}0.994|\mathrm{R}-\mathrm{B}|+0.961 \mid \mathrm{G} \\
-\mathrm{B}|+0.914| \mathrm{G}-\mathrm{R} \mid\end{array}$ \\
\hline $\begin{array}{l}\text { Normalized Difference Vegetation } \\
\text { Index }\end{array}$ & NDVI & $(N I R-r) /(N I R+r)$ \\
\hline $\begin{array}{l}\text { Green-Normalized Difference } \\
\text { Vegetation Index }\end{array}$ & GNDVI & $(\mathrm{NIR}-\mathrm{g}) /(\mathrm{NIR}+\mathrm{g})$ \\
\hline Soil Adjusted Vegetation Index & SAVI & $\begin{array}{c}{[(\mathrm{NIR}-\mathrm{r}) /(\mathrm{NIR}+} \\
\mathrm{r}+\mathrm{L})](1+\mathrm{L})\end{array}$ \\
\hline
\end{tabular}

Table 1: Colour indices and vegetation indices

All the images were processed using a Matlab image processing toolbox. Parallel to photography, SPAD data as ground based reading were recorded by inserting the middle portion of the index leaf in the slit of the SPAD meter. Readings from fifteen randomly selected plants were collected from each lot and the average was calculated. Moreover, the locations of each plant was determined and recorded by GPS Juno ${ }^{\mathrm{TM}}$ ST handheld which is one of the products of Trimble Company with an accuracy of $2.5-5 \mathrm{~m}$ to collect coordinate points.

\subsection{Model Performance Analysis}

Analysis of variance (ANOVA) was used for the experiment to analysis the significant difference between treatments. Moreover, the normality of the distribution of standardized residuals for each variable was tested using the Shapiro-Wilk test. Meanwhile, a simple linear regression was employed to determine the strength of the relationship between the SPAD measurements and the indices. The coefficient of determination $\left(\mathrm{r}^{2}\right)$ was used to compare the performance of the indices.

\section{RESULTS AND DISCUSSION}

\subsection{Correlation of SPAD Reading and indices}

The descriptive statistic for SPAD reading in 71DAP presented in Table 2. The summary statistic indicated that the SPAD reading information could be collected intensively. The $\mathrm{CV}$ value was $7 \%$, this shows that the entire study area was homogenous.

The calculated colour indices from the UAV imagery are presented in Table 3. The CV showed that ExR varied the most as compared to other measured indices. Also GLI, DGCI, VisNIR indices (NDVI, GNDVI and SAVI) and $\mathrm{I}_{\mathrm{PCA}}$ tended to be more homogenous than the other studied indices, respectively.

As a prior step to model development for estimating $\mathrm{N}$ and chlorophyll content by using digital colour image processing, Pear-son two-tailed correlation between the colour indices and the SPAD measurements at 71 DAP was used for the correlation (Table 4).

Despite the output of analysis of correlation between CM values and colour indices for the leaf scale, all colour indices were not correlated with $\mathrm{CM}$ values at the canopy scale. For example, the correlation coefficient between $\mathrm{CM}$ values and $\mathrm{I}_{\mathrm{KAW}}$ was $-0.446^{* *}$ for the leaf scale at 71 DAP, whereas it was not correlated for the canopy scale $(r=0.058$ n.s.). However, most indices associated with $\mathrm{G}$ band show significant correlation such as ExG, ExGR, GLI and GRVI. Moreover, it indicates that digital images in JPEG format acquired by digital cameras with a built-in enhancement function have more sensitivity to the $G$ band. This could be due to Bayer filter array, which combines a blue, a red and two green sensor cells into one true-colour image pixel. In other words, CCDs are more sensitive to green colour, because the number of green pixels are twice the number of red and blue pixels in a true colour image.

There was a significant correlation between Vis-NIR indices and leaf chlorophyll meter value. Also there was a significant negative correlation found between $\mathrm{I}_{\mathrm{PCA}}$ and SPAD readings. Correlation between Both $\mathrm{I}_{\mathrm{PCA}}$ and Vis-NIR indices and leaf chlorophyll meters are much greater than other investigated colour indices. Therefore, it can be concluded that $\mathrm{I}_{\mathrm{PCA}}$, which uses three visible bands, has the capability to determine the status of $\mathrm{N}$ and chlorophyll content similar to Vis-NIR indices. This conclusion is in agreement with reports from a study by Hunt et al (2013), which proposed that all three visible bands in a vegetation index can improve the sensitivity for determining the status of chlorophyll content, if the method of data acquisition and analysis exploit the high spatial resolution available from LARS platforms.

\begin{tabular}{|l|l|}
\hline & SPAD (71DAP) \\
\hline Mean & 34.195 \\
Median & 34.21 \\
Mode & 35.20 \\
Standard deviation & 2.541 \\
Variance & 6.460 \\
Coefficient of variation(CV) & 0.074 \\
Minimum & 30.10 \\
Maximum & 38.10 \\
\hline
\end{tabular}

Table2: Descriptive statistics for SPAD reading in 71DAP

\begin{tabular}{|l|l|l|l|}
\hline Abbrev. & Mean & Std. error & CV $(\%)$ \\
\hline NGRDI & 0.123 & 0.015 & 39 \\
I $_{\text {KAW }}$ & 0.190 & 0.009 & 17.8 \\
ExR & 0.016 & 0.015 & 333.3 \\
ExB & 0.23 & 0.012 & 17.8 \\
ExG & 0.584 & 0.020 & 12.15 \\
ExGR & 0.568 & 0.035 & 21.4 \\
GRVI & 0.151 & 0.009 & 22.5 \\
DGCI & 0.468 & 0.010 & 7.6 \\
RGRI & 0.801 & 0.026 & 11.3 \\
GLI & 0.275 & 0.023 & 2.98 \\
VARI & 0.152 & 0.024 & 5.52 \\
I PCA & 150.29 & 4.163 & 9.5 \\
NDVI & 0.757 & 0.015 & 7.17 \\
GNDVI & 0.753 & 0.015 & 7.10 \\
SAVI & 0.758 & 0.015 & 7 \\
\hline
\end{tabular}

Table3: Descriptive statistic for vegetation indices in 71 DAP

\begin{tabular}{|l|l|}
\hline Index & $\mathrm{r}$ \\
\hline NGRDI & $-0.030^{\text {n.s. }}$ \\
I $_{\text {KAW }}$ & $0.058^{\text {n.s. }}$ \\
ExR & $0.621^{*}$ \\
ExB & $0.528^{\text {n.s. }}$ \\
ExG & $-0.672^{*}$ \\
ExGR & $-0.666^{*}$ \\
GRVI & $-0.645^{*}$ \\
DGCI & $-0.38^{\text {n.s. }}$ \\
RGRI & $-0.60^{\text {n.s. }}$ \\
GLI & $-0.642^{*}$ \\
VARI & $0.138^{\text {n.s. }}$ \\
IPCA & $-0.789^{* *}$ \\
NDVI & $0.785^{* *}$ \\
GNDVI & $0.783^{* *}$ \\
SAVI & $0.749^{* *}$ \\
\hline
\end{tabular}


Table4: Correlation coefficient for indices derived from UAV imagery versus SPAD

\section{CONCLUSION}

The results of this study indicate that the conventional colour digital camera could be employed for fast and accurate, nondestructive measurement and determination of the status of $\mathrm{N}$ and chlorophyll content in rice plant.

This study revealed that a close association between new developed index $\left(\mathrm{I}_{\mathrm{PCA}}\right)$ and chlorophyll meter values, which provides another index for determining the chlorophyll and $\mathrm{N}$ content in the leaves of rice plant in paddy fields at various growth stages.

Radio controlled aerial vehicle based on the LARS system was used to acquire image using a commercial compact digital camera in visible bands and Tetracam agriculture digital camera in visible-NIR bands over a rice canopy at the altitude to $100 \mathrm{~m}$ to estimate chlorophyll content. Results of this study indicated that the LARS platform could be a promising replacement for satellite and airborne platforms for estimating $\mathrm{N}$ and chlorophyll content. The relationship between the most estimated indices and SPAD values indicated that LARS platform can be applied for estimating $\mathrm{N}$ and chlorophyll content during mid-season in paddy fields. A low cost LARS system would be well suited for high spatial and temporal resolution images and data analysis for proper assessment of rice growth. Finally, this study could be extended further for different rice varieties along with other key nutrients such as $\mathrm{P}$ and $\mathrm{K}$ at critical growth stages to improve final yield in rice cultivation.

\section{ACKNOWLEDGEMENTS}

The authors acknowledge the financial support of the Ministry of Education, Youth and Sport of the Czech Republic - projects 'CENAKVA' (No. CZ.1.05/2.1.00/01.0024), 'CENAKVA II' (No. LO1205 under the NPU I program).

\section{REFERENCES}

Aber, J. S., Aaviksoo, K., Karofeld, E., and Aber, S. W. 2002. Patterns in Estonian bogs as depicted in colour kite aerial photographs. Suo., 53(1), 1-15.

Bajwa, S. G., and Mozzaffari, M. 2007. Effect of N availability on vegetative index of cotton canopy: A spatial regression approach. Trans. ASABE, 50(5), 1883-1892

Canisius, F., Turral, H., and Molden, D. 2007. Fourier analysis of historical NOAA time series data to estimate bimodal agriculture. . International Journal of Remote Sensing, 28(24), 5503-5522.

Cao, Q., Miao, Y., Wang, H., Huang, S., and Cheng, S. 2013. Non-destructive estimation of rice plant nitrogen status with crop circle multispectral active canopy sensor. Field Crops Research, 154, 133-144

Cartelat, A., Cerovic, Z., Goulas, Y., Meyer, S., Lelarge, C., Prioul, J. L., Barbottin, A., Jeuffroy, M. H., Gate, P., Agati, G., and Moya, I. 2005. Optically assessed contents of leaf polyphenolics and chlorophyll as indicators of nitrogen deficiency in wheat (Triticum aestivum L.). Field Crops Research, 91(1), 35-49.

Fageria, N., K., and Baligar, V.C., 2005, enhancing nitrogen use efficiency in crop plants. Advances in Agronomy, 88, pp97-185.
Gholizadeh, A., Amin, M. S. M., Anuar, A. R., Aimrun, W., and Saberioon, M. M. 2011. Temporal Variability of SPAD Chlorophyll Meter Readings and its Relationship to Total Nitrogen in Leaves within a Malaysian Paddy Field. Australian Journal of Basic Applied Science, 5(5), 236-245.

Hansen, P. M., and Schjoerring, J. K. 2003. Reflectance measurement of canopy biomass and nitrogen status in wheat crops using normalized difference vegetation indices and partial least squares regression. Remote Sensing Environment, 86(4), 542-553.

Huber, D. M., and Thompson, I. A. 2007. Nitrogen and plant disease. In L. E. Datnoff, W. H. Elmer, and D. M. Huber (Eds.), Mineral Nutrition and Plant Disease (pp. 31-44). St. Paul, Minn.: The American Psychopathological Society.

Hunt Jr., E. R., Cavigelli, M., Daughtry, C. S., McMurtrey, J. E., and Walthall, C. L. 2005. Evaluation of digital photography from model aircraft for remote sensing of crop biomass and nitrogen status. Precision Agriculture, 6(4), 359-378.

Hunt Jr., E. R., Doraiswamy, P., McMurtrey, J. E., Daughtry, C. S., Perry, E. M., and Akhmedov, B. 2013. A visible band index for remote sensing leaf chlorophyll content at the canopy scale. Int. J. Applied Earth Observation Geoinformation., 21, 103-112.

Jensen, T., Apan, A., Young, F., and Zeller, L. 2007. Detecting the attributes of a wheat crop using digital imagery acquired from a low-altitude platform. Computers and Electron. Agric., 59(1-2), 66-77.

Johanson, G. V., Raun, W. R., Solie, J., and Marvin, S. 2002. Managing nitrogen fertilizer using a nitrogen rich strip: Projected profitability. Departments of plant and soil science and biosystems and agriculture engineering, Stillwater, Okla.: Oklahoma State University. Retrieved from http://www.nue.okstate.edu/Extensio/Managing_N_Fert.htm

Lee, K. J., and Lee, B. W. 2013. Estimation of rice growth and nitrogen nutrition status using colour digital camera image analysis. European Journal of Agronomy. 48, 57-65.

Lee, Y. J., Yang, C. M., Chang, K. W., and Shen, Y. 2008. A simple spectral index using reflectance of $735 \mathrm{~nm}$ to assess nitrogen status of rice canopy. Agronomy Journal, 100(1), 205212 .

Lelong, C. C., Burger, P., Jubelin, G., Roux, B., Labbe, S., and Barett, F. (2008). Assessment of unmanned aerial vehicles imagery for quantitative monitoring of wheat crop in small plots. Sensors, 8, 3557-3585.

Link, A., and Reusch, S. 2006. Implementation of site-specific nitrogen application Status and development of the YARA NSensor. NJF Seminar 390, Precision Technology in Crop Production Implementation and Benefits (pp. 37-41). Stockholm, Sweden: Norsk Jernbaneforbund.

Mercado-Luna, A., Rico-Garcia, E., Lara-Herrera, A., SotoZarazua, G., Ocampo-Velazquez, R., Guevara-Gonzalez, R., and Herrera-Ruiz, G. (2010). Nitrogen determination on tomato (Lycopersicon esculentum Mill.) seedlings by colour image analysis (RGB). African Journal of Biotechnology, 9(33), 53265332 .

Pagola, M., Ortiz, R., Irigoyen, I., Bustince, H., Barrenechea, E., and Aparicio-Tejo, P. 2009. New method to assess barley 
nitrogen nutrition status based on image colour analysis. Computers and Electronics in Agriculture, 65(2), 213-218.

Primicerio, J., Gennaro, S. F., Fiorillo, E., Genesio, L., Lugato, E., and Matese, A. 2012. A flexible unmanned aerial vehicle for precision agriculture. Precision Agriculture, 13(4), 517-523.

Rorie, R. L., Purcell, L. C., Karcher, D. E., and King, C. A. 2011a. The assessment of leaf nitrogen in corn from digital images. Crop Science, 51(5), 2174.

Rorie, R. L., Purcell, L. C., Mozaffari, M., Karcher, D. E., King, C. A., Marsh, M. C., and Longer, D. E. 2011b. Association of "greenness" in corn with yield and leaf nitrogen concentration. Agronomy Journal, 103(2), 529-535.

Samseemoung, G., Soni, P., Jayasuriya, H. P. W., and Salokhe, V. M. 2012. Application of low altitude remote sensing (LARS) platform for monitoring crop growth and weed infestation in a soybean plantation. Precision Agriculture, 13(6), 611-627.

Swain, K. C., Thomso, H. P., and Jayasuriya, H. P. 2010. Adoption of an unmanned helicopter for low altitude remote sensing to estimate yield and total biomass. Transactions of ASABE, 53(1), 21-27.

Teoh, C. C., Hassan, D. A., Radzali, M. M., and Jafni, J. J. 2012. Prediction of SPAD chlorophyll meter readings using remote sensing technique. Journal of Tropical Agriculture and Food Science, 40(1), 127-136

Varinderpal-Singh, Bijay-Singh, Yadvinder-Singh, Thind, $\mathrm{H}$. S., and Gupta, R. K. 2010. Need based nitrogen management using the chlorophyll meter and leaf colour chart in rice and wheat in South Asia: a review. Nutrient Cycling in Agroecosysems. 88(3), 361-380.

Vericat, D., Brasington, J., Wheaton, J., and Cowie, M. 2008. Accuracy assessment of aerial photographs acquired using lighter-than-air blimps: Low-cost tools for mapping river corridors. River Research Applications, 25(8), 985-1000.

Xue, L., Cao, W., Zhu, Y., and Dai, T. 2004. Monitoring leaf nitrogen status in rice with canopy spectral reflectance. Agronomy Journals, 96(1), 135-142. 